\title{
Can Competition Spoil Reciprocity? - A Laboratory Experiment
}

\author{
Stefan Bauernschuster \\ Oliver Falck \\ Niels Große
}

CESIFO WORKING PAPER NO. 2923

CAtegory 2: Public ChOICE

JANUARY 2010

\footnotetext{
An electronic version of the paper may be downloaded

- from the SSRN website:

www.SSRN.com

- from the RePEc website:

- from the CESifo website:

www.RePEc.org

www.CESifo-group.org/wp
} 


\title{
Can Competition Spoil Reciprocity? - A Laboratory Experiment
}

\begin{abstract}
This paper investigates how group membership and competition among trustors interact with trust and trustworthiness in a laboratory one-shot trust game. To analyze these effects, we apply a $2 \times 2$ design. We induce group membership by letting subjects play coordination games with clear focal points, leading to higher investments and trustworthiness. Introducing competition leads to a decrease in trustworthiness, especially among partners. We argue that once competition comes into play, trustees perceive trustors' investments as the outcomes of a competitive bidding process rather than good intentions, which reduces reciprocity.
\end{abstract}

JEL-Code: C92, G11, Z13, L14.

Keywords: trust, reciprocity, investment game, group membership, competition.

Stefan Bauernschuster

Ifo Institute for Economic Research at the University of Munich

Poschingerstrasse 5

Germany-81679 Munich

bauernschuster@ifo.de
Oliver Falck

Ifo Institute for Economic Research at the University of Munich

Poschingerstrasse 5

Germany-81679 Munich

falck@ifo.de

\author{
Niels Große \\ GSBC EIC (DFG RTG 1411) \\ at the University of Jena \\ Carl-Zeiss-Strasse 3 \\ Germany-07743 Jena \\ Niels.Daniel.Grosse@uni-jena.de
}

This version: January 2010

We are indebted to Nick Feltovich, Werner Güth, Hans Hvide, Oliver Kirchkamp, Martin Kocher, Jörg Oechssler, George Panos, Helmut Rainer, Gerhard Riener, Klaus Schmidt, Utz Weitzel, and participants of the 2009 Ringberg Conference of the Max Planck Institute of Economics and the ESA conference in Innsbruck for insightful comments that helped to improve this paper. Financial support by the German Research Foundation is gratefully acknowledged. 


\section{Introduction}

Economists have shown in a variety of settings that people show a substantial degree of reciprocity and do not behave merely selfish. For example, in the trust game set up by Berg et al. (1995), trusting investors can generally rely on the trustworthiness, i.e., the reciprocity, of trustees. However, little is known about the underlying motivational forces driving reciprocity. Does reciprocity in the trust game depend on how trustees evaluate trustors' intentions? If so, does competition affect these perceptions and which effects does this in turn have on reciprocity? Since competition is one of the main features of every market economy, the lack of systematic research about the interaction of competition on the one hand and reciprocity on the other hand seems puzzling.

In this paper, we tackle the question of how competition between two investors interacts with trust and trustworthiness in simple one-shot trust games. We apply a 2 x 2 between-subjects treatment design and analyze these interactions while distinguishing between (baseline) trust and trustworthiness among strangers and (directed) trust and trustworthiness among partners. In order to artificially induce a feeling of group membership for partners in the laboratory, we modify existing approaches, like communication between subjects, by playing coordination games with clear focal points. This form of reduced communication offers partners common successful experiences and thus induces group feelings among subjects in the laboratory. Indeed, in the standard two-person trust game we find that partners display higher levels of trust than strangers. Introducing competition among trustors does not significantly increase sent amounts. However, trustees react to competition between trustors by lowering return ratios; this effect is particularly strong and significant for directed trustworthiness. This observed reaction to competition is in line with intention-based theories of reciprocity. Accordingly, we suggest that once competition comes into play, trustees perceive trustors' sent amounts as the outcomes of a competitive bidding process rather than genuine trust, which crowds out reciprocity.

To investigate the effect of competition on trust and trustworthiness, we deliberately choose a laboratory experiment. Although one might argue that measuring trust and trustworthiness could well be done with real world data, for example by looking at credit markets, there are at least two reasons why we have chosen the experimental method. First, credit defaulting could be interpreted as a lack of trustworthiness; however, it does not necessarily imply it and might occur without the intention of the debtor. Second, competition emerges endogenously in the field. As a consequence, often only spurious effects of competition on outcome variables can be obtained by analyzing real world data while laboratory experiments allow isolating 
treatment effects of exogenously imposed competition. McIntosh et al. (2005) use panel data in an attempt to tackle these endogeneity problems and investigate the effects of competition in Ugandan microfinance markets. They find a decrease in repayment performance to incumbent firms, which they ascribe to clients now taking loans from several lenders simultaneously. However, it is not exactly known to which degree the results are driven by selection of borrowers into incumbent firms and entries or market entry decisions of competitors. McIntosh et al. (2005) also point out that their market is a market which is not saturated and that the effects of competition might be even stronger in more saturated markets. Additionally, as argued above, we do not exactly know to what extend credit defaults can be ascribed to a lack of trustworthiness. These issues make us believe that we might learn interesting details about the effects of competition on trust and trustworthiness in a more controlled laboratory setting.

The remainder of the paper is organized in the following way: Section 2 gives a short review of the related literature embedding the cornerstones of our experiment. Section 3 describes our experimental design in detail and section 4 states our hypotheses. The experimental results are presented in section 5. Section 6 concludes.

\section{Background}

Why should we care about trust and trustworthiness in the first place? After the seminal work of Putnam et al. (1993), a growing body of research has found that the level of trust among agents is correlated with a wide range of economic outcomes, such as economic growth (Knack and Keefer, 1997), job search (Mouw, 2003; Bayer et al., 2008), firm location, or (entrepreneurial) finance (Michelacci and Silva, 2007; Sanders and Nee, 1996; McMillan and Woodruff, 1999). While all these studies deal with the effects of trust and trustworthiness, Glaeser et al. (2002) investigate the mechanism underlying the creation of these factors. Berg et al. (1995) show experimentally that the majority of subjects place trust in the trustees and that this trust is reciprocated by trustworthiness. Results of this game were replicated in a variety of settings (cf. Camerer, 2003). Especially trustworthiness as measured in the trust game and to a lesser degree trusting behavior correlates with attitudes of trust, real life social connections (Glaeser et. al., 2000) and financial transactions in the field. For example, Karlan (2005) finds that trustworthy behavior in the trust game is a valid predictor of loan repayments among members of a Peruvian rotating savings and credit association. However, at present there is scarce knowledge about how personal relationships and attachment to fellow peers are affected by policies or market structure (cf. Tabellini, 2008). 
The sociological literature stresses the fact that group membership structures interpersonal interaction and results in trust and trustworthiness as a form of social capital (Coleman, 1988). In economics, the concept of social identity defined as the degree to which individuals see themselves as members of a group has recently gained attention following the seminal papers by Akerlof and Kranton (2000, 2005). They argue that the degree to which agents feel attached to each other and consider themselves members of the same group has important implications for trust and trustworthiness. Therefore, we look at both, baseline trust and trustworthiness among strangers as well as directed trust and trustworthiness among partners to investigate the effects of competition in our laboratory experiment. Experimental research has dealt with both the effect of natural (e.g., Goette et. al., 2006) and artificially induced groups (e.g., Chen and Li, 2009) in a variety of games. The introduction of natural groups e.g., by names that signal ethnic origin - leads to discrimination in trust games based on expectations of trustworthiness (Fershtman and Gneezy, 2001). ${ }^{1}$ Similarly, the introduction of artificially induced groups by color group assignment leads to discrimination of outsiders in a repeated trust game, where subjects play sequentially with other subjects of the in-group and of the out-group (Hargreaves Heap and Zizzo, 2009). ${ }^{2}$ In their experiment, color group assignment does not lead to significantly higher in-group trust or trustworthiness compared to a control group without artificially induced groups. In this paper, we introduce an alternative and to the best of our knowledge novel method of inducing group membership in the laboratory. In addition to color group assignment, subjects go through a group-building phase by playing coordination games that have a clear focal point (Schelling, 1960) as a solution. These games ensure a common successful experience, which signals as little as possible about a partner's trustworthiness, as coordination succeeds in the large majority of cases. Our results show that this way of group building might indeed be a worthwhile alternative to the so far established methods.

In our main treatments, we let trustees choose between stranger and partner trustors. Prior research has shown that group membership does not only have an effect on behavior toward others in the game, it also leads to discrimination through partner choice. For example, Slonim (2004) finds little evidence of discrimination by trustors based on gender in trust games but significant evidence of discrimination in partner selection. Slonim and Garbarino (2008) reach similar results with gender and age as possible criteria for partner selection. As a consequence, discrimination may not only lead to lower earnings in a bilateral game but also

\footnotetext{
${ }^{1}$ Fershtman and Gneezy (2001) find that only men respond strongly to ethnic stereotypes.

${ }^{2}$ See similarly Buchan et al. (2006) on the effects of communication and color group assignment to induce trust in several countries. In their setting, trust could be induced even with non-strategy-relevant communication.
} 
to lost opportunities of interaction in the presence of partner selection. So far, the modest attention on partner choice in the trust game has focused on choices made by trustors to select trustworthy trustees (e.g., Bornhorst et al., 2004). Huck et al. (2006) look at the effects of competition among trustees and information about past rounds behavior in a repeated trust game which leads to higher efficiency. Cassar and Rigdon (2009) study trust and trustworthiness in three-node networks with two senders and one receiver, and one sender and two receivers, respectively. Subjects play forty rounds in one treatment and are randomly rematched in every round. They find that the signal of trust is comparative and can be leveraged under full information; under full information trust increases in the two senders network and trustworthiness increases in the two receivers network. In their study Cassar and Rigdon (2009) do not implement partner choice or group membership. In contrast to this stream of research, we are the first to investigate the effect of partner choice by trustees and competition among investors; this is done in one-shot trust games to avoid any reputation and learning effects. Additionally, we allow for heterogeneous reactions of trustees toward stranger and partner investors. To the best of our knowledge, both effects have not been looked at before. ${ }^{3}$

Pure outcome-based models (Fehr and Schmidt, 1999; Bolton and Ockenfels, 2000) suggest that competition should have no effects on trustworthiness since reciprocity is determined solely by distributional motivations. However, competition among trustors may have detrimental effects on reciprocity if reciprocal behavior is based on the interpretation of intentions (McCabe et al., 2003; Dufwenberg and Kirchsteiger, 2004; Falk and Fischbacher, 2006). With competition among trustors, trustees might find it harder to interpret the behavior of trustors as genuinely trusting and rather ascribe the sending behavior to strategic considerations in a competitive bidding process among trustors. Very similar arguments have been put forward by Brandts and Charness (2005). In experimental gift-exchange markets, they "perhaps surprisingly" - as they stress - do not find that behavior is substantially affected by changes in the degree of competition. Our experiment is clearly related to Brandts and Charness (2005) but differs in at least three points. First, we do not conduct a giftexchange game but a trust game. We consider this deviation minor since at the end of the day, the structure of the gift exchange game is very similar to the trust game. Second, in contrast to Brandts and Charness (2005), we analyze the effects of competition on reciprocal behavior in one-shot games and thus do not allow for reputation building in a repeated setting. And third,

\footnotetext{
${ }^{3}$ In contrast to the trust game, the effects of supply side and demand side competition on fairness considerations have been more systematically investigated in other games. Competition in ultimatum bargaining seems to lead to more unfair distributions (e.g., Roth et al., 1991; see Fehr and Schmidt, 1999, or Fehr and Schmidt, 2006, for a discussion).
} 
we allow for heterogeneous effects of competition with respect to group membership since competition might affect strangers and partners in different ways.

\section{Experimental Design}

The experiment was conducted in May 2009 in the computer laboratory of the FriedrichSchiller-University Jena. All subjects were undergraduate students of this university, coming from a wide variety of majors. Subjects were recruited on-line via ORSEE (Greiner, 2004). Overall, 248 subjects participated in 14 sessions. The outline of the experiment was provided to subjects in printed form. Detailed instructions, the experiment and a final questionnaire were computerized with the use of zTree (Fischbacher, 2007). Translated instructions are provided in the appendix. The experiment consisted of four stages. In stages one to three, all subjects participated in different kinds of coordination games. Thereafter, subjects entered a one-shot trust game being the final stage of the experiment. All stages of the experiment were paid according to the subjects' decisions. Depending on assigned role and treatment, subjects had the opportunity to answer up to two bonus questions, where they could earn another $0.10 €$ for each correct answer. On average, subjects earned 7.56€.

\section{Experimental Treatments}

In order to identify the effects of competition on trust and trustworthiness of partners and strangers, we implemented four distinct experimental treatments, which can roughly be characterized as altering group size and group composition in the trust game. More specifically, treatments were implemented so that the final stage was a standard two-person trust game with strangers (S-S), a two-person trust game with partners (P-P), a three-person trust game with two stranger trustors (SS-S), and three-person trust game with a choice between a partner trustor and a stranger trustor (SP-P). Table 1 gives a graphical representation of this $2 \times 2$ design where I stands for the first mover ("trustor") and II for second mover ("trustee"). We ran three sessions per treatment S-S and P-P with nine groups per sessions and four sessions per treatment SS-S and SP-P with six groups per session. All sessions were conducted with 18 subjects each, except for one session each of treatment P-P and treatment S-S, where we had to restrict the number of subjects to 16 due to no-shows. 
Table 1: Treatment overview

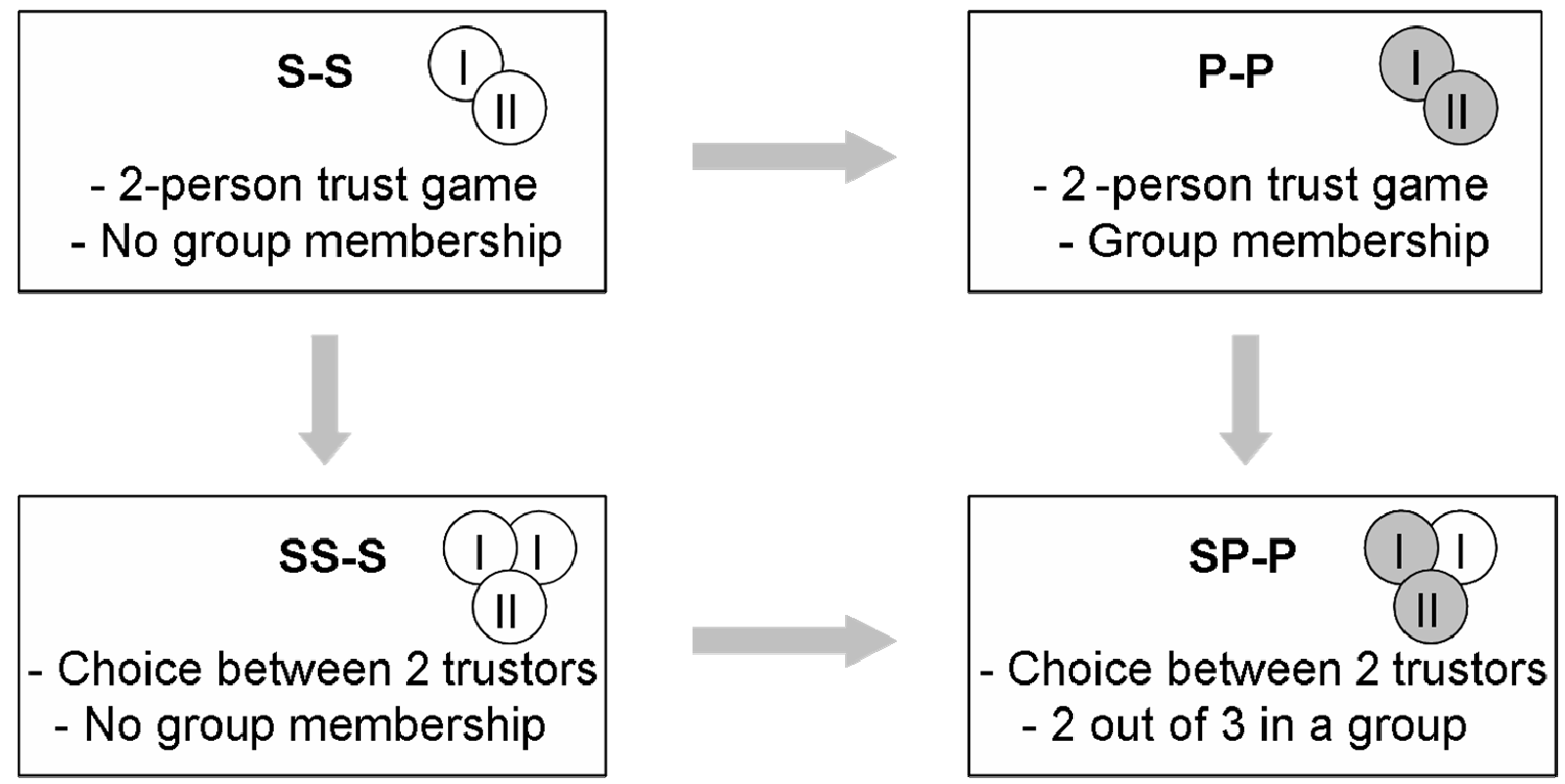

Notes: I=first mover (trustor/investor), $\mathrm{II}=$ second mover (trustee); light grey color marks partners; S-S stands for "stranger - stranger" and is short for the 2-person trust game with a stranger trustor and a stranger trustee, P-P stands for "partner - partner" and is short for the 2-person trust game with a partner trustor and a partner trustee, SS-S stands for "stranger, stranger - stranger" and is short for the 3-person trust game with two stranger trustors and a stranger trustee, SP-P stands for "stranger, partner - partner" and is short for the 3-person trust game with a partner trustor, a stranger trustor and a partner trustee.

\section{Stages 1 to 3: Coordination Games}

In these stages of the experiment, all subjects played three incentivized two-person coordination games. The first coordination game was framed as a choice of meeting points in Jena. One of the two alternatives was a clear focal point ("Ernst-Abbe-Platz"), i.e., the place in front of the central campus cafeteria, whereas the other alternative ("Eichplatz", a parking lot in the city center) was not. Subjects were paid $0.25 €$ each in case of a successful meeting. In the second coordination game, the subjects were asked to put the letters "A," "B," and "C" in a specific order. If both subjects could coordinate on the same order, they were paid $0.50 €$ each. The focal point in this game was the alphabetical order. The final coordination game again was framed as a choice of meeting points. However, this time it was no meeting point in Jena but in Paris, France. Subjects could choose between the Eiffel Tower and the Centre Georges Pompidou, where we regarded the first alternative as the focal point. In case of a successful meeting, subjects were paid $1.00 €$ each. Thus, in sum, subjects could earn $1.75 €$ in these three coordination games.

At the beginning of the experiment, groups of two were formed randomly. In treatments where two players are supposed to interact as partners in the final stage (the trust game), we artificially induced group membership by letting the subjects stay together for the whole experiment. In treatment P-P, all subjects interacted with the same partner in all three 
coordination games (stage one to three) as well as in the trust game (stage four). This means, we induced group membership in all groups of treatment P-P. In treatment SP-P, two out of three subjects interacted with each other in the coordination games as well as the trust game. This is to say, we induced group membership in two thirds of all groups, i.e., all groups whose members also interacted in the trust game. In all other cases, subjects were reassigned to new groups in every single stage of the experiment, and group membership was not induced.

The aim of these coordination games was to produce both common experience on the basis of some joint cognitive effort as well as common success among subjects that later on would be partners in the trust game. In addition to playing three coordination games together, we applied some more strategies to induce a feeling of group membership. First, group members in treatments P-P and SP-P were referred to as "partners." Second, the same color was assigned to all members of the same group, and subjects were informed about this color assignment. Third, all group members in treatment P-P and SP-P were informed that they and their partners jointly earned an amount of $0.50 €, 1.00 €$, or $2.00 €$ respectively, if they were successful in the three coordination games. They were also informed that this joint profit was split equally among the two group members. In cases where we did not want to induce group membership, subjects were informed that they could earn $0.25 €, 0.50 €$, and $1.00 €$ respectively, if they succeeded in playing the coordination games. All group members were informed before the first stage that they would stay with their partners for the rest of the experiment. All other subjects were informed that they were randomly assigned to new subjects in every single stage of the experiment. In treatment P-P, group members received feedback about the choice of their partners and the jointly earned profit. In treatment SP-P, only those groups whose members also would interact in the final trust game received feedback about the choice of their partners and the earned payoffs. All other subjects did not receive any feedback about the choices of partners and the earned profits until the end of the experiment.

We are aware that the way of inducing group membership might generate substantial demand effects. However, this is true for all the experiments in which group membership is artificially induced. Therefore, if we still find a negative effect of competition on reciprocity toward a partner despite these demand effects, this would support our point additionally.

\section{Stage 4: Trust Game}

In the final stage of the experiment, we implemented a Berg et al. (1995) trust game with slight modifications across treatments. The roles of trustor and trustee were randomly 
assigned for this game and subjects were informed about their roles just before the trust game. The trustor and the trustee each receive an initial endowment of $4 €$. The trustor can decide how many euros (if any) to send to the trustee. The sent amount is called $s$ and has to be a multiple of $0.1 €$. The trustee can then decide whether he wants to accept or reject the offer of the trustor. ${ }^{4}$ If the trustee rejects the offer, $s$ is returned to the trustor and the game ends. If the trustee accepts the offer, $s$ is tripled and given to the trustee. The trustee then decides how many euros (if any) to return to the trustor. The trustee is restricted to return at most $3 \mathrm{~s}$ to the trustor; the returned amount $r$ has to be a multiple of $0.1 €$.

$$
\begin{aligned}
& s \in[0,4] \\
& r \in[0,3 s]
\end{aligned}
$$

Thus, the payoffs $\pi$ of the trustor and the trustee are:

$$
\begin{aligned}
& \pi_{\text {trustor }}=4-s+r \\
& \pi_{\text {trustee }}=4+3 s-r
\end{aligned}
$$

The amount sent by the trustor measures the level of trust, whereas the fraction returned to the trustor by the trustee can be interpreted as trustworthiness.

\section{2-Person Trust Game with Strangers (Treatment S-S)}

This treatment presents the baseline case of the experiment. Groups of two are randomly formed at the beginning, and trustor and trustee are neutrally referred to as "sender" and "receiver." After the sending decision, we elicit the trustor's belief about the returned amount with an incentivized bonus question. In case of right guess, a subject earns an additional $0.10 €$.

\section{2-Person Trust Game with Partners (Treatment P-P)}

Again, we have groups of two. But in contrast to the treatment S-S, all subjects stay in the same group, in the coordination games as well as in the final trust game. In this treatment, trustor and trustee are referred to as "partners" as they have already been referred to during the coordination games. Subjects are reminded that they play the trust game together with their partners from the previous stages and that the partner is a member of the same color

\footnotetext{
${ }^{4}$ We implement this decision to be able to compare the two-player trust games with the three-player trustorchoice treatments SP-P and SS-S without introducing effects that can be ascribed to selecting partners per se.
} 
group. Again, we elicit the trustor's belief about the returned amount with a bonus question asked after the sending decision, again incentivized with $0.10 €$.

\section{3-Person Trust Game with Choice between Stranger Trustors (Treatment SS-S)}

In this treatment, we introduce a choice between two trustors, A and B. Groups of three are randomly formed and roles of trustor and trustee randomly assigned. Thus, we extend the original trust game to a three-person game. Similar to the standard trust game, the two trustors and the trustee each receive an amount of $4 €$. Then trustors decide simultaneously how many euros (if any) to send to the trustor. We call the sent amounts $\mathrm{s}_{\mathrm{A}}$ and $\mathrm{s}_{\mathrm{B}}$. Subsequently, the trustee can decide whether he accepts $\mathrm{s}_{\mathrm{A}}$ or $\mathrm{s}_{\mathrm{B}}$ or neither of the two offers. If the trustee rejects both offers, $\mathrm{s}_{\mathrm{A}}$ and $\mathrm{s}_{\mathrm{B}}$ are returned to their senders and the game ends. If the trustee accepts an offer, the accepted amount is tripled and sent to the trustee while the rejected offer is returned to its sender. Finally, the trustee can decide how many euros (if any) to keep and how many euros (if any) to return to the trustor whose offer was accepted. For example, if the trustee accepts $\mathrm{s}_{\mathrm{A}}, \mathrm{s}_{\mathrm{B}}$ is returned to trustor $\mathrm{B}$, and the trustee can return an amount up to three times $\mathrm{s}_{\mathrm{A}}$ to trustor A. Trustors are informed that there is another trustor and that only one of the two offers can be accepted by the trustee. In this treatment, we elicited the beliefs of trustors about the returned amount in the case of acceptance of the offer and about the amount sent by the other trustor by means of bonus questions, each incentivized with $0.10 €$.

\section{3-Person Trust Game with Choice between Partner and Stranger Trustor (Treatment SP-P)}

In this treatment, the game is the same as the three-person game in treatment SS-S. However, now, trustor $\mathrm{A}$ and the trustee have gained some common experience in the previous coordination games, just like subjects in P-P. However, there is also trustor B who could offer an amount $\mathrm{s}_{\mathrm{B}}$ to the trustee. As in treatment SS-S, both trustors are informed about the existence of the other trustor. Additionally, participants are informed that A and the trustee have previous experience from the coordination games and are assigned to the same color group while B does not have any previous experience with the trustee and is not assigned to the same color group. After the trustors' sending decisions, we elicited their beliefs about the returned amount in the case of acceptance of the offer and about the amount sent by the other trustor by means of bonus questions, each incentivized with $0.10 €$.

\footnotetext{
${ }^{5}$ We deliberately chose not to play a three-person trust game with choice between two partner trustors since the induction of group membership with three partners would naturally deviate from the way of group induction with two partners and thus possibly blur the comparability of treatments.
} 


\section{Hypotheses}

The standard prediction based on rational self-interested individuals is that in the one-shot trust game we should observe no returns $r$ that are greater than zero if agents only care about their own payoff and the game is not repeated. However, if trustors anticipate this behavior of the trustees, backward induction leads us to a situation where we observe no investments $s$ of trustors in trustees in the first place because trustors do not expect do get a return on their investment. Thus, the subgame perfect outcome is the same across all our treatments and can be described as:

$$
\begin{aligned}
& s=0 \\
& r=0
\end{aligned}
$$

This would leave us with a situation where both trustor and trustee keep their initial endowments $e$.

Contradicting this prediction, behavioral economics suggest that we should find a joint improvement to this subgame perfect outcome. Investors put trust in the trustee and take the risk of investing an amount that is greater than zero. Since this amount is tripled, both parties can reach a Pareto superior situation compared to the subgame perfect outcome. Reciprocity makes the trustee return an amount that is larger than zero and often larger than the initial investment. In a setting where trustor and trustees have no previous experience, as in treatment S-S, we call the trust placed in the trustee baseline trust and the trustworthiness of the trustee baseline trustworthiness.

Hypothesis 1a: Baseline trust among members of the subject pool leads to investments of the trustors that are greater than zero in the S-S treatment.

Hypothesis 1b: Baseline reciprocity toward members of the subject pool leads to return rates of the trustees that are greater than zero in the S-S treatment.

If we are successful in inducing a feeling of group membership in the laboratory, we should observe higher investments as well as higher return rates in the P-P treatment as compared to the S-S treatment. We call this additional trust placed in partners directed trust and the additional trustworthy behavior of partners directed trustworthiness. 
Hypothesis 2a: Directed trust that is built up through common experience leads to higher investments of the trustors in the P-P treatment as compared to the S-S treatment.

Hypothesis 2b: Common experience leads to directed trustworthiness in the form of higher return rates of the trustees in the P-P treatment as compared to the S-S treatment.

Trustors may hold heterogeneous beliefs about the degree of trustworthiness that are reflected in different investment offers. If we introduce competition of trustors in the standard trust game framework, realized investments rise as the trustee can choose among the offered investments of two trustors, accepting the highest offer. If beliefs about trustworthiness are on average right, competition among trustors should lead to a situation similar to the winner's curse in which the chosen trustor systematically overestimates the trustworthiness of the trustee (cf. Thaler 1988). Following this line of argument, realized investments should increase while average sent amounts by trustors should stay unchanged. At the same time, trust might not be separable from competition as trustors now face a strategic interaction among each other about the opportunity to invest. Depending on their beliefs about the other trustor's behavior and the trustworthiness of the trustee, trustors may increase their offers in a competitive bidding process. ${ }^{6}$

Hypothesis 3: Realized investments in a competitive environment increase since trustees can choose the highest of two offered investments. This leads to higher realized investments in the three-person game as compared to the two-person game.

Competition among trustors might also affect the interpretation of trustors' behavior by the trustee. We do not know much about the motivational forces lying behind reciprocity. However, if the perception of trustors' intentions matters for trustees' reciprocity, we might expect a decline in reciprocity in our competition treatments. The reasoning behind this hypothesis is that in competition treatments, trustees might ascribe investment behavior to a strategic interaction with competitive bidding among trustors and not to good intentions based on genuine trust, which might in turn crowd out reciprocity (see, e.g., McCabe et al. 2003).

\footnotetext{
${ }^{6}$ Note that the same mechanism might also lead to a decrease in investment as trustors are discouraged to make offers.
} 
Hypothesis 4: Reciprocity in the form of trustworthiness of trustees toward trustors declines in a three-person game since trustors' offers are seen as driven by a competitive race rather than genuine trusting behavior based on good intentions.

\section{Results}

\section{The Coordination Games}

Descriptive statistics show that our coordination games indeed had focal points on which subjects were able to coordinate. 97.6 percent of them chose Ernst-Abbe-Platz instead of Eichplatz as the common meeting point in Jena, which led to a successful meeting in 95.2 percent of all cases. The second coordination game, in which subjects were asked to put the letters A, B, and C in a certain order, proved to be slightly more difficult but we can still discern a clear focal point: 85.1 percent of all subjects chose the alphabetical order. As a result, 75.8 percent of all groups successfully coordinated, out of which 96.8 percent chose the alphabetical order, with the remaining 3.2 percent coordinating on the order A, C, B. In the final coordination game, 96.8 percent of all subjects chose the Eiffel Tower as a meeting point in Paris, which led to a successful coordination in 92.7 percent of the groups.

\section{The Trust Game}

As a first step in the analysis of the trust games, we look at simple bubble plots showing amounts returned to the trustors by the trustees conditional on their investments (Graph 1). Note that the graphs only contain information on those subjects whose contracts were accepted by the trustee. Across all treatments we find positive investments as well as positive returned amounts. The diagonal lines are 45 degree lines, signifying a return ratio equal to one. The size of the bubble corresponds to the frequency of observations. Comparing the treatments, some striking preliminary patterns are observable. In the partner treatment P-P, more subjects invested their full endowments $(4 €)$ than in the baseline stranger treatment S-S. Additionally, these high investments in the treatment P-P were often reciprocated with a higher amount than $4 €$. Invested amounts lower than $2 €$ were a rare event (only 3 observations) in the treatment P-P while this occurred quite frequently in the treatment S-S. Returning less than was received was also a rare event (only 3 observations) in treatment P-P. Comparing the stranger competition treatment SS-S and the baseline stranger treatment S-S a 
shift in accepted investments from $2 €$ to higher investments (4€) is observable while there is no obvious pattern regarding the return ratio. In the treatment with asymmetric competition SP-P, we find no accepted amount lower than $2 €$. This pattern of investment in the asymmetric competition treatment SP-P is in line with the P-P treatment, but constitutes a change compared to the symmetric competition treatment SS-S. As in the symmetric competition SS-S, high investment (4€) was the modal amount in the asymmetric competition SP-P; however, more than half of these high investments were not reciprocated.

\section{Graph 1: Received and returned amounts}

S-S

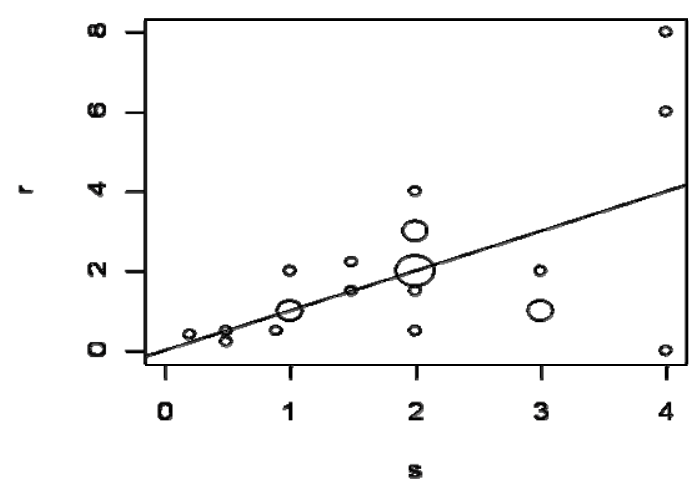

SS-S

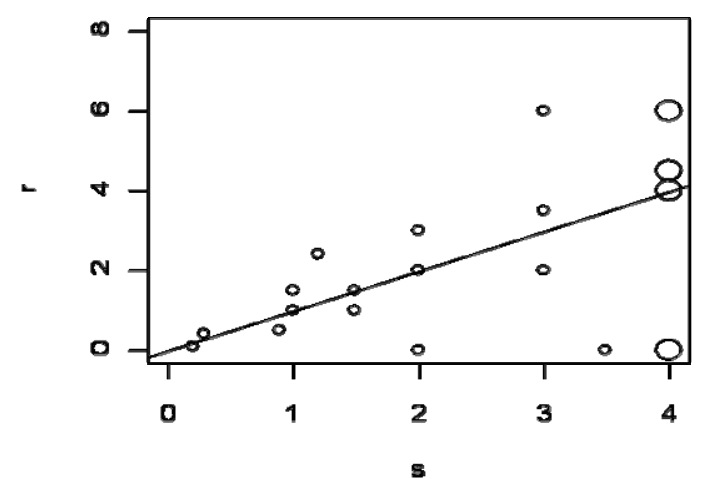

P-P

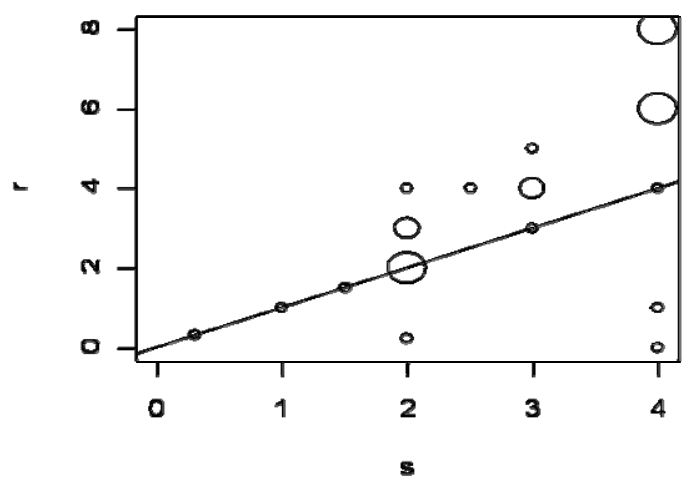

SP-P

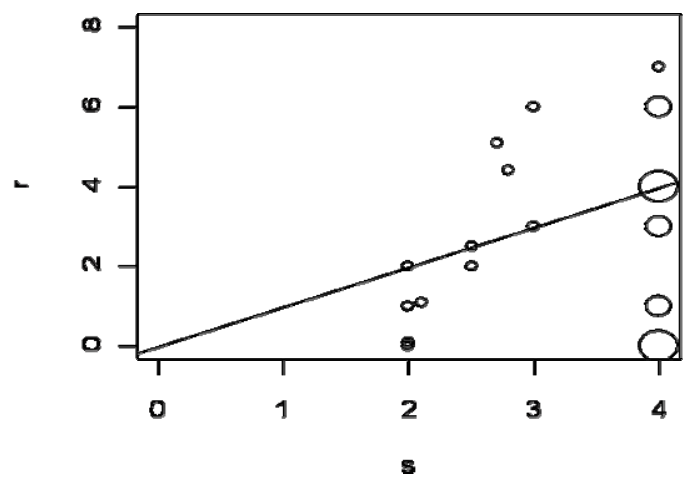

Notes: The x-axes show accepted sent amount in euros, the y-axes returned amounts in euros. Note that only accepted offers are included in the graphs. S-S stands for "stranger - stranger" and is short for the 2-person trust game with a stranger trustor and a stranger trustee, P-P stands for "partner - partner" and is short for the 2person trust game with a partner trustor and a partner trustee, SS-S stands for "stranger, stranger - stranger" and is short for the 3-person trust game with two stranger trustors and a stranger trustee, SP-P stands for "stranger, partner - partner" and is short for the 3-person trust game with a partner trustor, a stranger trustor and a partner trustee.

To obtain a more precise picture of the differences across treatments, we start with the trustor side and compare the means of the offered amounts across the different treatments and types. Table 2 presents the results of this exercise. In the S-S treatment, trustors on average offered 1.74 out of 4.00 euros. This is in stark contrast to the standard prediction based on self- 
interested individuals and in line with other behavioral studies. As a consequence, we can confirm Hypothesis 1a.

Result 1: Trustors display baseline trust, i.e., trustors send amounts to trustees which are greater than zero in treatment S-S.

Furthermore, our attempt to build up a feeling of group membership in the laboratory was successful. Trustors in the P-P treatment sent 2.59 out of 4.00 euros to their partners. The nonparametric Mann-Whitney two-sided test shows that this is significantly more than in the S-S treatment $(p=0.019)^{7}$, confirming our Hypothesis $2 a^{8}{ }^{8}$ OLS regressions show that the number of successful coordinations has a positive and significant effect on the amount sent by the partner trustor to the partner trustee. Using dummies for each coordination game instead of a single count variable, we find that it is successful coordination in the sorting letters coordination game which drives the effect. This is not surprising given that this coordination game is the one where we see most variation in coordination success with 25 percent of all subjects not being successful. The results of these regressions are available from the authors upon request.

Result 2: Feelings of group membership lead trustors to increase their investments. As a result, the level of directed trust in treatment $\mathrm{P}-\mathrm{P}$ is higher than the baseline trust level expressed in treatment S-S.

If we introduce competition between trustors in a framework where no group membership has been built up, we find no significant effect on the sending behavior of trustors (MannWhitney test, $\mathrm{p}=0.950)$. However, there is a tendency that stranger trustors increased their investments in a framework where they were confronted with a trustee and a trustor who had common experience. These stranger trustors might have felt that they had to increase their investments in order to have a chance of being chosen by the trustee who was a partner of the

\footnotetext{
${ }^{7}$ All Mann-Whitney test statistics in this paper result from two-sided tests.

${ }^{8}$ Even while running the experiment, we got the impression that our way of inducing social identity in the laboratory was successful. In the questionnaire submitted at the end of every session, several subjects in the P-P and SP-P sessions reported that they built up feelings of togetherness with their partners by playing these coordination games.
} 
competitor trustor. ${ }^{9}$ Still, the effect is not significant on the conventional confidence levels (Mann-Whitney test, $\mathrm{p}=0.139$ ). Moreover, we do not find that competition significantly changed the investments of partner trustors (Mann-Whitney test, $p=0.904$ ).

In all treatments, trustees had the opportunity to reject the trustors' offers. Therefore, we examine the trustees' choice of trustors before investigating realized investments. In the twoperson trust games, all offers above $0.10 €$ were accepted while offers below were rejected. This resulted in two rejections in the treatment P-P and three in the treatment S-S (see Table 2). In the three-person games, there was only a single occasion in the SS-S treatment in which both offers were rejected (offers were $0 €$ and $0.50 €$ ); in 47 out of 48 observations, one of the two offers was accepted. Partner choice in the three-person trust game was mainly based on offered amounts. In one occasion in the treatment SP-P, the partner was preferred although her offer was lower (offers were $2 €$ by the partner trustor and $3 €$ by the stranger trustor). Overall, in 46 out of 47 observations the selected trustor made an offer which was at least as high as or higher than the offer of the other trustor. Offers by trustors tied in two occasions in the asymmetric competition treatment SP-P; in both cases all trustors offered the full amount of $4 €$. The partner trustor was selected in one occasion and the stranger trustor in the other. From this pattern of partner choice we deduce that partner choice in our setting follows strict rationality in the vast majority of cases, i.e., positive amounts are accepted and higher offers are taken. Additionally, we do not observe an obvious preference for partners in the asymmetric competition.

Splitting the trustors into those whose offers were accepted and those whose offers were rejected, we find similar trends for both groups (see Table 2). Focusing on the offers that were accepted, we observe that competition tends to increase realized investments. This effect is statistically significant (Mann-Whitney test, $p=0.002$ ) when we compare the realized investments of stranger trustors in the S-S and SP-P treatments. It is not surprising that we find this effect to be largest in this constellation since competition is especially fierce for stranger trustors when they are confronted with a trustor who is a partner of the trustee.

\footnotetext{
${ }^{9}$ Indeed, stranger trustors' beliefs about the investments of their competitors are higher in treatment SP-P than in treatment SS-S (Mann-Whitney test, $\mathrm{p}=0.073$ ).
} 
Table 2: Investment behavior of trustors

\begin{tabular}{|c|c|c|c|c|c|c|}
\hline \multirow[b]{2}{*}{ Treatment } & \multicolumn{3}{|c|}{ Partner } & \multicolumn{3}{|c|}{ Stranger } \\
\hline & Accepted & Not accepted & Total & Accepted & Not accepted & Total \\
\hline \multirow[t]{3}{*}{ P-P } & 2.80 & 0 & 2.59 & & & \\
\hline & 1.12 & 0 & 1.32 & & & \\
\hline & (24) & (2) & (26) & & & \\
\hline \multirow[t]{3}{*}{ S-S } & & & & 1.96 & .03 & 1.74 \\
\hline & & & & 1.12 & .06 & 1.22 \\
\hline & & & & (23) & (3) & (26) \\
\hline \multirow[t]{3}{*}{ SS-S } & & & & 2.53 & 1.18 & 1.83 \\
\hline & & & & 1.37 & 1.16 & 1.42 \\
\hline & & & & (23) & (25) & (48) \\
\hline \multirow[t]{3}{*}{ SP-P } & 3.21 & 1.84 & 2.7 & 3.38 & 1.64 & 2.29 \\
\hline & .91 & 1.31 & 1.25 & .78 & 1.37 & 1.45 \\
\hline & (15) & (9) & (24) & (9) & (15) & (24) \\
\hline \multirow[t]{3}{*}{ Total } & 2.96 & 1.51 & 2.64 & 2.43 & 1.26 & 1.92 \\
\hline & 1.05 & 1.39 & 1.27 & 1.27 & 1.25 & 1.38 \\
\hline & (39) & (11) & (50) & (55) & (43) & (98) \\
\hline
\end{tabular}

Notes: The figures are mean amounts in euros, standard errors in italics, no. of observations in parentheses. S-S stands for "stranger - stranger" and is short for the 2-person trust game with a stranger trustor and a stranger trustee, P-P stands for "partner - partner" and is short for the 2-person trust game with a partner trustor and a partner trustee, SS-S stands for "stranger, stranger - stranger" and is short for the 3-person trust game with two stranger trustors and a stranger trustee, SP-P stands for "stranger, partner - partner" and is short for the 3-person trust game with a partner trustor, a stranger trustor and a partner trustee.

Turning to the return behavior of the trustees (see Table 3), our results again clearly contradict the selfish prediction. Because individuals' relationships are based on trust, on average the investment game functions well and we often find mutual gains. In the treatment S-S, where we did not induce group membership, trustees returned an amount greater than zero (1.97 euros). The returned amount in the treatment P-P is 3.58 euros and thus greater than the returned amount in the treatment S-S. A Mann-Whitney test shows that the difference is statistically significant $(\mathrm{p}=0.018)$. When we examine the effects of competition, we might argue that there is a slight tendency toward lower returns in the competition treatments for partner trustors, whereas the returns for stranger trustors tend to be higher as compared to the respective treatments without competition. However, of course, these figures cannot provide a clear picture of the trustworthiness of trustees in different frameworks as long as investments vary across treatments. 


\begin{tabular}{l|ccc}
\hline Treatment & Partner & Stranger & Total \\
\hline \hline P-P & 3.58 & & 3.58 \\
& 2.47 & & 2.47 \\
& $(24)$ & & $(24)$ \\
S-S & & 1.97 & 1.97 \\
& & 1.90 & 1.90 \\
& & $(23)$ & $(23)$ \\
SS-S & & & 2.34 \\
& & 2.34 & 2.09 \\
& & 2.09 & $(23)$ \\
SP-P & & $(23)$ & 2.76 \\
& 2.95 & & 2.22 \\
& 2.52 & 2.44 & $(24)$ \\
\hline Total & $(15)$ & 1.70 & 2.67 \\
& 3.34 & $(9)$ & 2.23 \\
& 2.47 & 2.20 & $(94)$ \\
\hline
\end{tabular}

Notes: The figures are mean amounts in euros, standard errors in italics, no. of observations in parentheses. S-S stands for "stranger - stranger" and is short for the 2-person trust game with a stranger trustor and a stranger trustee, P-P stands for "partner - partner" and is short for the 2-person trust game with a partner trustor and a partner trustee, SS-S stands for "stranger, stranger - stranger" and is short for the 3-person trust game with two stranger trustors and a stranger trustee, SP-P stands for "stranger, partner - partner" and is short for the 3-person trust game with a partner trustor, a stranger trustor and a partner trustee.

As long as we do not combine the return information with the original investment choices, the figures presented in Table 3 are difficult to interpret. This is why, as a next step, we analyze return ratios for trustors $r / s$, where $r$ is the amount the trustee returned and $s$ is the amount sent by the accepted trustor. Since we have no accepted zero investments, the ratio is computable for all observations. Table 4 presents simple mean return ratio comparisons across treatments. In the treatments without competition, the return ratio is greater for partner trustors than for their stranger counterparts. However, the difference is not statistically significant according to a Mann-Whitney rank sum test $(\mathrm{p}=0.203)$.

Result 3: Trustees display baseline trustworthiness, i.e., trustees return amounts to trustors which are greater than zero in treatment S-S. Directed trustworthiness in P-P tends to be greater than baseline trustworthiness in S-S; yet, this effect is not statistically significant.

Introducing competition between trustors in a framework where no group membership was built up does not alter the return ratio significantly, although we can observe a slight drop. This drop is more pronounced in the treatment SP-P. A comparison of the mean return ratios across the SP-P and P-P treatments yields the intriguing result that competition leads to 
crowding out of reciprocity for partners. The return ratio declines substantially from 1.24 to .88 for this group. A Mann-Whitney rank sum test proves this decline to be statistically significant $(\mathrm{p}=0.095)$. The return ratio for stranger trustors tends to decline as well if we compare the stranger treatment without competition S-S to the asymmetric competition treatment SP-P. However, this change is not statistically significant (Mann-Whitney test, $(\mathrm{p}=0.284)$, probably due to relatively low number of observations.

Table 4: Return ratios for trustors

\begin{tabular}{l|ccc}
\hline Treatment & Partner & Stranger & Total \\
\hline \hline IG & 1.24 & & 1.24 \\
& .56 & & .56 \\
& $(24)$ & & $(24)$ \\
OG & & 1.05 & 1.05 \\
& & .61 & .61 \\
& & $(23)$ & $(23)$ \\
OC & & & .96 \\
& & .96 & .60 \\
& & .60 & $(23)$ \\
IOC & & $(23)$ & .84 \\
& .88 & & .63 \\
& .71 & .76 & $(24)$ \\
\hline Total & $(15)$ & .51 & 1.02 \\
& 1.10 & $(9)$ & .61 \\
& .64 & .97 & $(94)$ \\
\hline
\end{tabular}

Notes: The figures are mean amounts in euros, standard errors in italics, no. of observations in parentheses. S-S stands for "stranger - stranger" and is short for the 2-person trust game with a stranger trustor and a stranger trustee, P-P stands for "partner - partner" and is short for the 2-person trust game with a partner trustor and a partner trustee, SS-S stands for "stranger, stranger - stranger" and is short for the 3-person trust game with two stranger trustors and a stranger trustee, SP-P stands for "stranger, partner - partner" and is short for the 3-person trust game with a partner trustor, a stranger trustor and a partner trustee.

This finding of a crowding out effect corroborates our Hypothesis 4, at least for partners. Drawing on intention-based theories of reciprocity and following McCabe et al. (2003), we suggest that, with competition, investments of trustors are interpreted as the result of a competitive bidding process rather than genuine voluntary trust. This is why trustors do not reciprocate these investments with high return ratios anymore.

Result 4: Competition between trustors leads to a crowding out of reciprocity in the trust game. This effect is particularly strong for directed reciprocity between partners. 
Cassar and Rigdon (2009) argue that trust is comparative. Since we know that our trustees almost exclusively chose the trustor with the highest offered amount, we might expect that under competition, the trustor with the highest offered amount could benefit from being regarded more trusting than her competitior trustor, which should result in higher return ratios. However, interestingly this is not the case: The chosen trustors in the competition treatments receive lower return ratios than the chosen trustors in the two-person games. Thus, we suggest that any positive comparison effect might be overcompensated by the negative effect of competition, which makes sent amounts being regarded as the results of a competitive bidding process rather than genuine trust.

Table 5: Unfairly treated trustors

\begin{tabular}{l|ccc}
\hline & No & Unfairly treated & Tetal \\
\hline \hline Partner & & & \\
P-P & 21 & 3 & 24 \\
SP-P & 87.50 & 12.50 & 100.00 \\
& 9 & 6 & 15 \\
Stranger & 60.00 & 40.00 & 100.00 \\
S-S & 18 & 5 & 23 \\
& 78.26 & 21.74 & 100.00 \\
SS-S & 18 & 5 & 23 \\
& 78.26 & 21.74 & 100.00 \\
SP-P & 7 & 2 & 9 \\
& 77.78 & 22.22 & 100.00 \\
\hline
\end{tabular}

Notes: The figures are no. of observations, percentage shares in italics. S-S stands for "stranger - stranger" and is short for the 2-person trust game with a stranger trustor and a stranger trustee, P-P stands for "partner - partner" and is short for the 2-person trust game with a partner trustor and a partner trustee, SS-S stands for "stranger, stranger - stranger" and is short for the 3-person trust game with two stranger trustors and a stranger trustee, SP$\mathrm{P}$ stands for "stranger, partner - partner" and is short for the 3-person trust game with a partner trustor, a stranger trustor and a partner trustee.

As a further step, we investigate unfair return behavior, by which we define those return ratios that are not higher than .5 - this corresponds to the lower quartile of the overall return ratio distribution. ${ }^{10}$ Table 5 gives the absolute numbers and ratios of trustors who are treated unfairly, conditional on treatment and type, where type is partner or stranger. We find that roughly 22 percent of stranger trustors are treated unfairly, irrespective of the treatment. The situation is quite different for partner trustors. Whereas only 12 percent are unfairly treated in

\footnotetext{
${ }^{10}$ As an additional exercise, we define return ratios that are smaller than 1 as unfair return behavior. The results pattern does not substantially change with this definition. We see virtually no difference in unfair return behavior comparing treatments S-S and SS-S, a slight increase in unfair return behavior for strangers in treatment SP-P, yet a considerable increase for partners comparing treatment P-P to treatment SP-P.
} 
the treatment without competition (P-P), this ratio rises up to 40 percent in the competition treatment SP-P. Fisher's exact test shows that for partner trustors being unfairly treated by their partners is not independent of treatment ( $\mathrm{p}$-value: 0.063 ). The finding that the negative effects of competition on reciprocity is only statistically significant for partners is interesting and leaves room for further research. It might be worthwhile to investigate whether directed reciprocity is more sensitive to the interpretation of intentions than baseline reciprocity among strangers also in other settings.

Checking the accepted trustors' beliefs about the returns, we observe that, in general, beliefs are higher than the actual returns. However, there is a striking pattern in the data, suggesting that the gap between beliefs and actual returns becomes considerably larger once we introduce competition among trustors. This is to say, trustors tend to overestimate the reciprocity of their trustees in a competition framework. While the trustors' beliefs still have predictive power in treatments without competition, this power is lost in the competition treatments. This effect is especially prevailing in the treatment SP-P. Consistent with our previous findings, we also observe that partner trustors in the treatment P-P expect their partners to return significantly more than their stranger counterparts in the treatment S-S (p-value 0.053). Introducing competition does not affect the trustors' beliefs, neither in the strangers competition framework of treatment SS-S nor in the asymmetric competition framework of treatment SP-P. However, competition does affect the way investments, especially those of partners, are reciprocated by the trustees.

The investment and return behavior in the different treatments results in a payoff pattern as shown in Table 6. In comparison to other studies that use the trust game, in our study, too, the payoffs of the trustees are higher than the payoffs of the trustors. This difference in the payoffs between trustor and trustee becomes even larger once we introduce competition. The variance in payoffs is largest in the SP-P treatment, where we also observe crowding out of reciprocity. 
Table 6: Profits in the Trust Game

\begin{tabular}{|c|c|c|c|c|c|c|c|c|c|}
\hline \multirow[b]{2}{*}{ Treatment } & \multicolumn{3}{|c|}{ Partner trustor } & \multicolumn{3}{|c|}{ Stranger trustor } & \multirow[t]{2}{*}{ Partner trustee } & \multirow[t]{2}{*}{ Stranger trustee } & \multirow[b]{2}{*}{ Total } \\
\hline & Accepted & Not accepted & Total & Accepted & Not accepted & Total & & & \\
\hline \multirow[t]{3}{*}{ P-P } & 4.78 & 4 & 4.72 & & & & 8.46 & & 6.59 \\
\hline & 1.96 & 0 & 1.89 & & & & 2.83 & & 3.04 \\
\hline & $(24)$ & (2) & (26) & & & & $(26)$ & & (52) \\
\hline \multirow[t]{3}{*}{ S-S } & & & & 4.01 & 4 & 4.01 & & 7.46 & 5.73 \\
\hline & & & & 1.59 & 0 & 1.49 & & 2.92 & 2.88 \\
\hline & & & & (23) & (3) & $(26)$ & & $(26)$ & (52) \\
\hline \multirow[t]{3}{*}{ SS-S } & & & & 3.82 & 4 & 3.91 & & 9.02 & 5.61 \\
\hline & & & & 1.78 & 0 & 1.22 & & 3.55 & 3.31 \\
\hline & & & & (23) & (25) & (48) & & (24) & (72) \\
\hline \multirow[t]{3}{*}{ SP-P } & 3.73 & 4 & 3.83 & 3.07 & 4 & 3.65 & 11.07 & & 6.18 \\
\hline & 2.31 & 0 & 1.81 & 1.89 & 0 & 1.21 & 2.88 & & 4.04 \\
\hline & $(15)$ & (9) & $(24)$ & $(9)$ & $(15)$ & $(24)$ & $(24)$ & & $(72)$ \\
\hline
\end{tabular}

Notes: The figures are mean amounts in euros, standard errors in italics, no. of observations in parentheses. S-S stands for "stranger - stranger" and is short for the 2-person trust

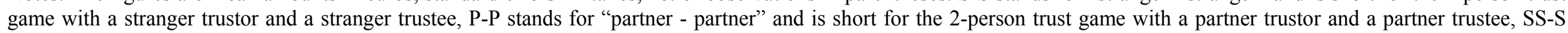
stands for "stranger, stranger - stranger" and is short for the 3-person trust game with two stranger trustors and a stranger trustee, SP-P stands for "stranger, partner - partner" and is short for the 3-person trust game with a partner trustor, a stranger trustor and a partner trustee. 


\section{Conclusions}

There is extensive literature in economics on the presence and relevance of trust and trustworthiness in a wide range of different settings. However, much less systematic research has been done on the question how market structure interacts with trust and trustworthiness. Our study is the first to analyze the effect of competition among stranger and partner trustors in one-shot trust games. We use a 2 × 2 treatment design to allow for heterogenous effects of competition on baseline trust and trustworthiness among strangers and directed trust and trustworthiness among partners. Group membership is induced by letting subjects play simple coordination games with focal points ensuring a common successful experience. To the best of our knowledge, this constitutes a novel way of inducing group membership in the laboratory. Our results suggest that competition does not significantly increase investments. However, trustees react to competition among trustors by lowering return ratios, with the effect being especially strong for partners. This effect can be interpreted as crowding out of reciprocity, in particular of directed reciprocity. In line with intention-based approaches of reciprocity, we suggest that once competition comes into play trustees perceive trustors' investments as the outcomes of a competitive bidding process rather than genuinely trusting behavior, which crowds out reciprocity.

Our analysis adds another piece of experimental evidence to the various, yet still not very systematic findings on the effects of competition on behavior. In our view, a step of utmost importance is the establishment of an economic theory which is able to explain under which conditions competition can support trust, trustworthiness and reciprocal behavior in general, and under which conditions competition has rather detrimental effects on these outcomes. 


\section{Appendix A: Instructions}

\section{A.1 Printed (English Translation)}

\section{Welcome to this experiment and thank you for your participation!}

In this experiment - financed by the German Research Foundation (DFG) - you can earn money, depending on your own performance and decisions. Therefore, it is important that you read these instructions carefully.

If you have any questions during the experiment, please raise your hand. We will then come to you and answer your question. Please pose your question quietly. All participants of this experiment receive the same printed instructions. The information on the screen, however, is only intended for the respective participant. Please do not look at the screens of other participants and do not talk to each other. If you offend against these rules, we are unfortunately required to expel you from the experiment. Please switch off your mobiles now.

\section{General Schedule}

The experiment comprises four stages. Every stage is fully relevant for your payoff. That is, your payment will be the sum of your results in all four stages.

You will receive detailed instructions for every stage during the experiment on your screen. Please read these instructions carefully.

The fourth stage of this experiment includes decisions for which simple calculations are necessary. To simplify these decisions a small calculator is integrated in the program. After your decision, you can press the button "Calculate without consequences" to learn about the consequences of your decision. After that, you can change your decision as you wish. Once you pressed the button "This is my final decision", your decision is final and no longer revisable.

A short questionnaire will follow after the experiment. Having filled out this questionnaire, please remain seated until we call you separately for payment.

\section{Further Schedule}

After you have read the instructions carefully, please wait for the other participants and then start with the computer program on your screen.

\section{Good luck!}




\title{
A.2 On-screen (English Translation)
}

\author{
Before stage 1 (treatment $P-P$ and partners in treatment $S P-P$ )
}

Welcome to this experiment!

You are a member of the red group.

You are assigned to a Partner, this partner is also a member of the red group

This partner remains your partner for the rest of the experiment.

The experiment comprises 4 stages.

You receive information on your payoff at the end of each stage.

Before stage 1 (treatment $S-S, S S-S$ and strangers in treatment $S P-P$ )

Welcome to this experiment!

On every stage of the experiment fellow players are randomly assigned to you.

The experiment comprises 4 stages.

You receive information on your payoff at the end of the experiment.

Stage 1/2/3 (treatment P-P and partners in treatment SP-P)

In this stage you play with your partner.

Only stage 1/3: Imagine, you and your partner have to meet in Jena/Paris. Where would you meet?

Only stage 2: Please sort the letters "A","B", and "C" as you wish!

You and your partner have to answer the same question at this moment.

If you both reach the same answer, you and your partner earn an amount of $1 € / 2 € / 4 €$.

This amount is split equally between you and your partner.

Only stage 1/3: Where do you want to meet your partner?

Only stage 2: How do you sort the letters?

Stage 1/2/3 (treatment $S-S, S S-S$ and strangers in treatment $S P-P$ )

You are assigned to a random fellow player.

Only stage 1/3: Imagine you and the fellow player have to meet in Jena/Paris. Where would you meet?

Only stage 2: Please sort the letters "A","B", and "C" as you wish!

You and your fellow player have to answer the same question at this moment

If you both reach the same answer, you each earn an amount of $0,50 € / 1 € / 2 €$.

Only stage 1/3: Where do you want to meet your fellow player?

Only stage 2: How do you sort the letters?

Stage 4: Trustors' information (treatment $S-S$ )

You are assigned to a random fellow player.

This randomly chosen player will be called "receiver".

You and the randomly chosen "receiver", each get the following amount in euros: 4

You can now decide how much you want to send to the "receiver".

If the "receiver" accepts your offer, the amount received is the tripled amount you sent.

After that, the "receiver" can decide how much of the tripled amount is returned to you.

If the "receiver" does not accept your offer, you will keep your amount of 4 euros. 


\section{Stage 4: Trustors' information (treatment P-P)}

In this stage you play with your partner.

You and your partner, each get the following amount in euros: 4

You can now decide how much you want to send to your partner.

If your partner accepts your offer, the amount received is the tripled amount you sent.

After that, your partner can decide how much of the tripled amount is returned to you.

If your partner does not accept your offer, you will keep your amount of 4 euros.

\section{Stage 4: Trustors' information (treatment SS-S)}

You are assigned to two random fellow players.

One randomly chosen player will be called "sender", the other "receiver".

You, the randomly chosen "receiver", and the "sender", each get the following amount in euros: 4

You can now decide how much you want to send to the "receiver".

At the same time, the "sender" decides how much to send to the "receiver".

The "receiver" can either accept your offer, the offer of the "sender" or none of the two offers.

If the "receiver" accepts an offer, the amount received is the tripled amount accepted.

After that, the "receiver" can decide how much of the tripled amount is returned to the one whose amount was accepted.

If the "receiver" does not accept your offer, you will keep your amount of 4 euros.

\section{Stage 4: Trustors' information (strangers in treatment SP-P)}

You are assigned to two random fellow players.

One randomly chosen player will be called "sender", the other "receiver".

The "sender" and the "receiver" know each other from the last three stages of this experiment. You, the randomly chosen "receiver", and the "sender", each get the following amount in euros: 4

You can now decide how much you want to send to the "receiver".

At the same time, the "sender" decides how much to send to the "receiver".

The "receiver" can either accept your offer, the offer of the "sender" or none of the two offers. If the "receiver" accepts an offer, the amount received is the tripled amount accepted.

After that, the "receiver" can decide how much of the tripled amount is returned to the one whose amount was accepted.

If the "receiver" does not accept your offer, you will keep your amount of 4 euros.

\section{Stage 4: Trustors' information (partners in treatment SP-P)}

In this stage you play with your partner.

Additionally, you are assigned to a random fellow player called "sender" who is not a member of the red group.

You, your partner, and the randomly chosen "sender", each get the following amount in euros: 4

You can now decide how much you want to send to your partner.

At the same time, the "sender" decides how much to send to your partner.

Your partner can either accept your offer, the offer of the "sender" or none of the two offers.

If your partner accepts an offer, the amount received is the tripled amount accepted.

After that, your partner can decide how much of the tripled amount is returned to the one whose amount was accepted.

If your partner does not accept your offer, you will keep your amount of 4 euros. 


\section{Stage 4: Trustees' information (treatment $S-S$ )}

You are assigned to a random fellow player.

This randomly chosen player will be called "sender"

You and the randomly chosen "sender", each get the following amount in euros: 4

The "sender" can now decide how much to send to you.

If you accept the "sender's" offer, this amount will be tripled and given to you.

After that, you can decide how much of the tripled amount you want to return to the "sender". If you do not accept the "sender's" offer, the "sender" will keep the amount of 4 euros.

Stage 4: Trustees' information (treatment P-P)

In this stage you play with your partner.

You and your partner, each get the following amount in euros: 4

Your partner can now decide how much to send to you.

If you accept your partner's offer, this amount will be tripled and given to you.

After that, you can decide how much of the tripled amount you want to return to your partner.

If you do not accept your partner's offer, your partner will keep the amount of 4 euros.

Stage 4: Trustors' information (treatment SS-S)

You are assigned to two random fellow players.

The two randomly chosen players will be called "senders".

You and the two randomly chosen "senders", each get the following amount in euros: 4

The two "senders" can now decide how much to send to you.

You can either accept one of the two offers or none of the two offers.

If you accept an offer, this amount will be tripled and given to you.

After that, you can decide how much of the tripled amount you want to return to the one whose amount you accepted.

If you do not accept an offer, the one whose offer was not accepted will keep the amount of 4 euros.

Stage 4: Trustors' information (treatment SP-P)

In this stage you play with your partner.

Additionally, you are assigned to a random fellow player called "sender" who is not a member of the red group.

You, your partner, and the randomly chosen "sender", each get the following amount in euros: 4

Your partner and the "sender" can now decide how much to send to you.

You can either accept one of the two offers or none of the two offers.

If you accept an offer, this amount will be tripled and given to you.

After that, you can decide how much of the tripled amount you want to return to the one whose amount you accepted.

If you do not accept an offer, the one whose offer was not accepted will keep the amount of 4 euros. 


\section{References}

Akerlof, George and Rachel Kranton (2000): Economics and Identity, Quarterly Journal of Economics, 115(3), 715-753.

Akerlof, George and Rachel Kranton (2005): Identity and the Economics of Organization, Journal of Economic Perspectives, 19(1), 9-32.

Bayer, Patrick, Stephen Ross, and Giorgio Topa (2008): Place of Work and Place of Residence: Informal Hiring Networks and Labor Market Outcomes, Journal of Political Economy (in press).

Berg, Joyce, John Dickhaut, and Kevin McCabe (1995): Trust, Reciprocity, and Social History, Games and Economic Behavior, 10, 122-142.

Bolton, Gary, and Axel Ockenfels (2000): ERC: A Theory of Equity, Reciprocity and Competition, American Economic Review, 90, 166-193.

Brandts, Jordi, and Gary Charness (2005): Do Labor Market Conditions Affect Gift Exchange? Some Experimental Evidence, The Economic Journal, 114, 684-708.

Bornhorst, Fabian, Andrea Ichino, Oliver Kirchkamp, Karl Schlag and Eyal Winter (2004): How do People Play a Repeated Trust Game? Experimental Evidence, University of Mannheim SFB 504 Discussion Paper 04-43.

Buchan, Nancy and Eric Johnson and Rachel Croson (2006): Let's get personal: An international examination of the influence of communication, culture and social distance on other regarding preferences, Journal of Economic Behavior and Organization, 60(3), $373-398$

Camerer, Colin (2003): Behavioral Game Theory - Experiments in Strategic Interaction, Princeton University Press.

Cassar, Alexandra, and Rigdon, Mary (2009): Trust and Trustworthiness in Networked Exchange, unpublished manuscript.

Chen, Yan and Sherry Li (2009): Group Identity and Social Preferences, American Economic Review, 99(1), 431-457.

Coleman, James (1988): Social Capital and the Creation of Human Capital, American Journal of Sociology, 94, Supplement, 95-120.

Dufwenberg, Martin and Georg Kirchsteiger (2004): A theory of sequential reciprocity, Games and Economic Behavior, 47(2), 268-298. 
Falk, Armin and Urs Fischbacher (2006): A theory of reciprocity, Games and Economic Behavior, 54(2), 293-315.

Fehr, Ernst and Klaus Schmidt (1999): A theory of fairness, competition, and cooperation, Quarterly Journal of Economics, 114, 817-868.

Fehr, Ernst and Klaus Schmidt (2006): The economics of fairness, reciprocity and altruism experimental evidence and new theories, in: Kolm, Serge-Christopher and Jean Ythier (eds.), Handbook of the economics of giving, altruism and reciprocity, North Holland.

Fershtman, Chaim and Uri Gneezy (2001): Discrimination in a Segmented Society - An Experimental Approach, Quarterly Journal of Economics, 116(1), 351-377.

Fischbacher, Urs (2007): z-Tree: Zurich Toolbox for Ready-made Economic Experiments, Experimental Economics, 10(2), 171-178.

Glaeser, Edward L., David Laibson, and Bruce Sacerdote (2002): An Economic Approach to Social Capital, Economic Journal, 112(483), 437-458.

Glaeser, Edward, David Laibson, José Scheinkman, and Christine Soutter (2000): Measuring Trust, Quarterly Journal of Economics, 115, 811-846.

Goette, Lorenz, David Huffman and Stephan Meier (2006): The Impact of Group Membership on Cooperation and Norm Enforcement: Evidence Using Random Assignment to Real Social Groups, American Economic Review, 96(2), 212-216.

Greiner, Ben (2004): An Online Recruitment System for Economic Experiments. In: Kurt Kremer, Volker Macho (eds.): Forschung und wissenschaftliches Rechnen 2003. GWDG Bericht 63, Göttingen : Ges. für Wiss. Datenverarbeitung, 79-93.

Hargreaves-Heap, Shaun and Daniel Zizzo (2009): The Value of Groups, American Economic Review, 99(1), 295-323.

Huck, Steffen, Gabriele Lünser, and Jean-Robert Tyran (2006) Competition fosters trust, CEPR Discussion Paper No. 6009.

Karlan, Dean (2005): Using Experimental Economics to Measure Social Capital and Predict Financial Decisions, American Economic Review, 95(5), 1688-1699.

Knack, Stephen and Philip Keefer (1997): Does Social Capital Have an Economic Payoff? A Cross-Country Investigation, Quarterly Journal of Economics, 112(4), 1251-1288.

McCabe, Kevin, Mary Rigdon, and Vernon Smith (2003): Positive Reciprocity and Intentions in Trust Games, Journal of Economic Behavior and Organization, 52, 267-275. 
McIntosh, Craig, Alain de Janvry and Elisabeth Sadoulet (2005): How Rising Competition Among Microfinance Institutions Affects Incumbent Lenders, The Economic Journal, $115,987-1004$.

McMillan, John and Christopher Woodruff (1999): Interfirm Relationships and Informal Credit in Vietnam, Quarterly Journal of Economics, 114, 1285-1320.

Michelacci, Claudio and Olmo Silva (2007): Why So Many Local Entrepreneurs?, Review of Economics and Statistics, 89(4), 615-633.

Mouw, Ted (2003): Social Capital and Finding a Job: Do Contacts Matter?, American Sociological Review, 68(6), 868-898.

Putnam, Robert D., Robert Leonardi, and Raffaella Y. Nanetti (1993): Making Democracy Work. Princeton: Princeton University Press.

Roth, Alvin, Vesna Prasnikar, Mashiro Okuno-Fujiwara, and Shmuel Zamir (1991): Bargaining and Market Behavior in Jerusalem, Ljubljana, Pittsburgh, and Tokyo: An Experimental Study, American Economic Review, 81(5), 1068-1095.

Sanders, Jimy M. and Victor Nee (1996): Immigrant Self-Employment: The Family as Social Capital and the Value of Human Capital, American Sociological Review, 61(2), 231249.

Schelling, Thomas (1960): The Strategy of Conflict, Harvard University Press.

Slonim, Robert (2004): Gender Selection Discrimination: Evidence from a Trust Game, Mimeo, Case Western Reserve University.

Slonim, Robert and Ellen Garbarino (2008): Increases in trust and altruism from partner selection: Experimental evidence, Experimental Economics, 11, 134-153.

Tabellini, Guido (2008): The Scope of Cooperation: Values and Incentives, Quarterly Journal of Economics, 123(3), 905-950. 


\section{CESifo Working Paper Series}

for full list see www.cesifo-group.org/wp

(address: Poschingerstr. 5, 81679 Munich, Germany, office@cesifo.de)

2861 Nina Czernich, Oliver Falck, Tobias Kretschmer and Ludger Woessmann, Broadband Infrastructure and Economic Growth, December 2009

2862 Evžen Kočenda and Martin Vojtek, Default Predictors and Credit Scoring Models for Retail Banking, December 2009

2863 Christian Gollier and Martin L. Weitzman, How Should the Distant Future be Discounted when Discount Rates are Uncertain?, December 2009

2864 Tiberiu Dragu and Mattias Polborn, Terrorism Prevention and Electoral Accountability, December 2009

2865 Torfinn Harding and Beata Smarzynska Javorcik, A Touch of Sophistication: FDI and Unit Values of Exports, December 2009

2866 Matthias Dischinger and Nadine Riedel, There's no Place like Home: The Profitability Gap between Headquarters and their Foreign Subsidiaries, December 2009

2867 Andreas Haufler and Frank Stähler, Tax Competition in a Simple Model with Heterogeneous Firms: How Larger Markets Reduce Profit Taxes, December 2009

2868 Steinar Holden, Do Choices Affect Preferences? Some Doubts and New Evidence, December 2009

2869 Alberto Asquer, On the many Ways Europeanization Matters: The Implementation of the Water Reform in Italy (1994-2006), December 2009

2870 Choudhry Tanveer Shehzad and Jakob De Haan, Financial Reform and Banking Crises, December 2009

2871 Annette Alstadsæter and Hans Henrik Sievertsen, The Consumption Value of Higher Education, December 2009

2872 Chris van Klaveren, Bernard van Praag and Henriette Maassen van den Brink, Collective Labor Supply of Native Dutch and Immigrant Households in the Netherlands, December 2009

2873 Burkhard Heer and Alfred Maußner, Computation of Business-Cycle Models with the Generalized Schur Method, December 2009

2874 Carlo Carraro, Enrica De Cian and Massimo Tavoni, Human Capital Formation and Global Warming Mitigation: Evidence from an Integrated Assessment Model, December 2009 
2875 André Grimaud, Gilles Lafforgue and Bertrand Magné, Climate Change Mitigation Options and Directed Technical Change: A Decentralized Equilibrium Analysis, December 2009

2876 Angel de la Fuente, A Mixed Splicing Procedure for Economic Time Series, December 2009

2877 Martin Schlotter, Guido Schwerdt and Ludger Woessmann, Econometric Methods for Causal Evaluation of Education Policies and Practices: A Non-Technical Guide, December 2009

2878 Mathias Dolls, Clemens Fuest and Andreas Peichl, Automatic Stabilizers and Economic Crisis: US vs. Europe, December 2009

2879 Tom Karkinsky and Nadine Riedel, Corporate Taxation and the Choice of Patent Location within Multinational Firms, December 2009

2880 Kai A. Konrad, Florian Morath and Wieland Müller, Taxation and Market Power, December 2009

2881 Marko Koethenbuerger and Michael Stimmelmayr, Corporate Taxation and Corporate Governance, December 2009

2882 Gebhard Kirchgässner, The Lost Popularity Function: Are Unemployment and Inflation no longer Relevant for the Behaviour of Germany Voters?, December 2009

2883 Marianna Belloc and Ugo Pagano, Politics-Business Interaction Paths, December 2009

2884 Wolfgang Buchholz, Richard Cornes and Dirk Rübbelke, Existence and Warr Neutrality for Matching Equilibria in a Public Good Economy: An Aggregative Game Approach, December 2009

2885 Charles A.E. Goodhart, Carolina Osorio and Dimitrios P. Tsomocos, Analysis of Monetary Policy and Financial Stability: A New Paradigm, December 2009

2886 Thomas Aronsson and Erkki Koskela, Outsourcing, Public Input Provision and Policy Cooperation, December 2009

2887 Andreas Ortmann, "The Way in which an Experiment is Conducted is Unbelievably Important": On the Experimentation Practices of Economists and Psychologists, December 2009

2888 Andreas Irmen, Population Aging and the Direction of Technical Change, December 2009

2889 Wolf-Heimo Grieben and Fuat Şener, Labor Unions, Globalization, and Mercantilism, December 2009

2890 Conny Wunsch, Optimal Use of Labor Market Policies: The Role of Job Search Assistance, December 2009 
2891 Claudia Buch, Cathérine Tahmee Koch and Michael Kötter, Margins of International Banking: Is there a Productivity Pecking Order in Banking, too?, December 2009

2892 Shafik Hebous and Alfons J. Weichenrieder, Debt Financing and Sharp Currency Depreciations: Wholly vs. Partially Owned Multinational Affiliates, December 2009

2893 Johannes Binswanger and Daniel Schunk, What is an Adequate Standard of Living during Retirement?, December 2009

2894 Armin Falk and James J. Heckman, Lab Experiments are a Major Source of Knowledge in the Social Sciences, December 2009

2895 Hartmut Egger and Daniel Etzel, The Impact of Trade on Employment, Welfare, and Income Distribution in Unionized General Oligopolistic Equilibrium, December 2009

2896 Julian Rauchdobler, Rupert Sausgruber and Jean-Robert Tyran, Voting on Thresholds for Public Goods: Experimental Evidence, December 2009

2897 Michael McBride and Stergios Skaperdas, Conflict, Settlement, and the Shadow of the Future, December 2009

2898 Ben J. Heijdra and Laurie S. M. Reijnders, Economic Growth and Longevity Risk with Adverse Selection, December 2009

2899 Johannes Becker, Taxation of Foreign Profits with Heterogeneous Multinational Firms, December 2009

2900 Douglas Gale and Piero Gottardi, Illiquidity and Under-Valuation of Firms, December 2009

2901 Donatella Gatti, Christophe Rault and Anne-Gaël Vaubourg, Unemployment and Finance: How do Financial and Labour Market Factors Interact?, December 2009

2902 Arno Riedl, Behavioral and Experimental Economics Can Inform Public Policy: Some Thoughts, December 2009

2903 Wilhelm K. Kohler and Marcel Smolka, Global Sourcing Decisions and Firm Productivity: Evidence from Spain, December 2009

2904 Marcel Gérard and Fernando M. M. Ruiz, Corporate Taxation and the Impact of Governance, Political and Economic Factors, December 2009

2905 Mikael Priks, The Effect of Surveillance Cameras on Crime: Evidence from the Stockholm Subway, December 2009

2906 Xavier Vives, Asset Auctions, Information, and Liquidity, January 2010

2907 Edwin van der Werf, Unilateral Climate Policy, Asymmetric Backstop Adoption, and Carbon Leakage in a Two-Region Hotelling Model, January 2010 
2908 Margarita Katsimi and Vassilis Sarantides, Do Elections Affect the Composition of Fiscal Policy?, January 2010

2909 Rolf Golombek, Mads Greaker and Michael Hoel, Climate Policy without Commitment, January 2010

2910 Sascha O. Becker and Ludger Woessmann, The Effect of Protestantism on Education before the Industrialization: Evidence from 1816 Prussia, January 2010

2911 Michael Berlemann, Marco Oestmann and Marcel Thum, Demographic Change and Bank Profitability. Empirical Evidence from German Savings Banks, January 2010

2912 Øystein Foros, Hans Jarle Kind and Greg Shaffer, Mergers and Partial Ownership, January 2010

2913 Sean Holly, M. Hashem Pesaran and Takashi Yamagata, Spatial and Temporal Diffusion of House Prices in the UK, January 2010

2914 Christian Keuschnigg and Evelyn Ribi, Profit Taxation and Finance Constraints, January 2010

2915 Hendrik Vrijburg and Ruud A. de Mooij, Enhanced Cooperation in an Asymmetric Model of Tax Competition, January 2010

2916 Volker Meier and Martin Werding, Ageing and the Welfare State: Securing Sustainability, January 2010

2917 Thushyanthan Baskaran and Zohal Hessami, Globalization, Redistribution, and the Composition of Public Education Expenditures, January 2010

2918 Angel de la Fuente, Testing, not Modelling, the Impact of Cohesion Support: A Theoretical Framework and some Preliminary Results for the Spanish Regions, January 2010

2919 Bruno S. Frey and Paolo Pamini, World Heritage: Where Are We? An Empirical Analysis, January 2010

2920 Susanne Ek and Bertil Holmlund, Family Job Search, Wage Bargaining, and Optimal Unemployment Insurance, January 2010

2921 Mariagiovanna Baccara, Allan Collard-Wexler, Leonardo Felli and Leeat Yariv, Gender and Racial Biases: Evidence from Child Adoption, January 2010

2922 Kurt R. Brekke, Roberto Cellini, Luigi Siciliani and Odd Rune Straume, Competition and Quality in Regulated Markets with Sluggish Demand, January 2010

2923 Stefan Bauernschuster, Oliver Falck and Niels Große, Can Competition Spoil Reciprocity? - A Laboratory Experiment, January 2010 